\title{
The pharmacotherapy preferred by doctors in treatment of patients diagnosed with asthma or chronic obstructive pulmonary disease or allergic rhinitis and concomitant diseases: an epidemiological analysis
}

\author{
Marcin Nowak르, Grzegorz Brożek², Zbigniew Doniec³, Magdalena Olszanecka-Glinianowicz ${ }^{4}$ \\ ${ }^{1}$ Adamed Ltd., Pienkow, Poland \\ ${ }^{2}$ Department of Epidemiology, College of Medicine in Katowice, Medical University of Silesia, Katowice, Poland \\ ${ }^{3}$ Institute of Tuberculosis and Lung Diseases, Rabka Zdroj, Poland \\ ${ }^{4}$ Health Promotion and Obesity Management Unit, Department of Pathophysiology, Medical Faculty in Katowice, Medical University \\ of Silesia, Katowice, Poland
}

Adv Dermatol Allergol 2017; XXXIV (2): 148-158

DOI:https://doi.org/10.5114/ada.2017.67081

\begin{abstract}
Introduction: The clinical course of asthma and chronic obstructive pulmonary disease (COPD) is influenced by the co-occurrence of other chronic diseases and their pharmacotherapy. There are no data associated with the doctors' pharmacotherapy preferences in treatment of patients with asthma, COPD or allergic rhinitis and concomitant diseases.

Aim: The assessment of doctors' preferences in pharmacotherapy of asthma, COPD or allergic rhinitis in relation to concomitant diseases.

Material and methods: General practitioners, pulmonologists, allergists, laryngologists and paediatricians $(n=319)$ participated in a questionnaire survey concerning their preferences in pharmacotherapy of asthma, COPD and allergic rhinitis in relation to concomitant diseases enrolling 11,310 patients with asthma, COPD and allergic rhinitis. Results: The concomitant diseases were reported in $58.5 \%$ of patients with asthma, $80.8 \%$ of patients with COPD and $46.4 \%$ of patients with allergic rhinitis. Patients with asthma were most frequently treated with inhaled glucocorticosteroids. However, in the subgroups with concomitant diseases, an increased usage of inhaled long-acting $\beta_{2}$-mimetics was noted. Regardless of comorbidities, patients with COPD were most frequently treated with inhaled long-acting $\beta_{2}$-mimetics whereas patients with allergic rhinitis - with nasal glucocorticosteroids and thirdgeneration antihistamines.

Conclusions: The co-occurrence of chronic diseases was most frequent among patients diagnosed with COPD. The treatment of asthma, COPD and allergic rhinitis is consistent with international recommendations and the occurrence of concomitant diseases did not significantly influence therapeutic preferences and decisions.
\end{abstract}

Key words: asthma, chronic obstructive pulmonary disease, allergic rhinitis, concomitant diseases, pharmacotherapy, preferences.

\section{Introduction}

Asthma is a chronic inflammation disease with an accompanying, increased bronchial sensitivity. The frequency of asthma in Poland is estimated at 10.6\% [1]. Direct and indirect annual costs of asthma treatment in the European Union are estimated at EUR 30 billion.

The appropriate pharmacotherapy allows obtaining control over asthma and minimizes its impact on pa- tients' daily functioning [2]. The occurrence of asthma in patients with various comorbidities deteriorates their quality of life [3] and increases not only the frequency of the disease exacerbations [4] but also the rate of death in the period of 30 days following the hospitalization due such to exacerbations [5]. In this group, comorbidities such as: chronic bronchitis, chronic obstructive pulmonary disease (COPD), chronic sinusitis, stomach ulcers,

Address for correspondence: Prof. Magdalena Olszanecka-Glinianowicz MD, PhD, Health Promotion and Obesity Management Unit, Department of Pathophysiology, Medical University of Silesia, 18 Medykow St, 40-752 Katowice, Poland, phone/fax: +48 322526091 , e-mail: magolsza@gmail.com Received: 21.02.2017, accepted: 6.03.2017. 
cardiovascular disease, osteoporosis, diabetes, depression and cancer are more frequent than in the general population [6-9]. However, the most common comorbidities observed in patients with asthma are other allergic diseases such as allergic rhinitis and conjunctivitis [10, 11]. Chronic sinusitis is more frequent among patients with severe asthma than in those suffering from its mild form [12]. Asthma is also a risk factor for COPD development. It is estimated that the coexistence of COPD occurs in $20 \%$ of patients diagnosed with asthma and that the likelihood of this coexistence increases with age [13]. The deterioration of the ventilation parameters in older patients is an independent risk factor for fatal cardiovascular events [14]. Also, the risk of hypertension [15] and ischemic brain events [16] is increased in patients with asthma. Furthermore, a higher prevalence of asthma is observed among patients with obesity and type 2 diabetes [17-21]. In addition the sleep apnoea syndrome, gastroesophageal reflux disease and depression were shown to increase the frequency of asthma exacerbations [19-24].

According to the GINA recommendations, the severity of asthma should determine the selection of pharmacotherapy, while the difficulties in asthma control, despite intensification of pharmacotherapy, should encourage the search for concomitant diseases as well as the lack of compliance.

The COPD is a chronic disease, characterized by longlasting bronchial obstruction accompanied by a chronic inflammatory response to toxic molecules and gases [25, 26]. The frequency of COPD, confirmed by spirometry, is $8.9 \%$ in the population aged over 40 years old [26], with the disease's morbidity increasing over time [27]. It is estimated that COPD will be the third most common cause of death in 2020 [28]. The comorbidities such as type 2 diabetes and ischemic heart disease are the cause of increased frequency of COPD exacerbations necessitating hospitalization [29]. In addition, an increased frequency of both depression and anxiety was found among COPD patients [30]. Moreover, the anxiety associated with dyspnoea is an independent risk factor for hospitalization in COPD exacerbations [31, 32], while depression is a risk factor for death in patients with COPD [31, 32]. Therefore, the choice of pharmacotherapy in COPD patients should be based on the COPD category in accordance with the GOLD recommendations, but also individualized taking into account other contraindications.

The frequency of allergic rhinitis is estimated at $5-17 \%$ in children aged 6-7 years old [33]. According to other studies, yearly allergic rhinitis occurred in $2.1 \%$ of children and $3.0 \%$ of adults, whereas seasonal in $8.9 \%$ of children and $8.7 \%$ of adults [34-37]. It has been shown that both direct and indirect costs associated with allergic rhinitis are high [38]. The disease does not cause serious complications but it does deteriorate the quality of life as well as decreases the productivity at work [39,
40]. It should be noted that among patients with allergic rhinitis, the occurrence of asthma is higher than in the general population. Therefore, the effective treatment of allergic rhinitis is crucial.

As mentioned above, the clinical course of asthma and COPD may be modified by comorbidities. Thus, an individual pharmacotherapy strategy should be considered. There are no data assessing the doctors' therapeutic preferences in patients with asthma, COPD or allergic rhinitis and comorbidities. Moreover, there are no data on the impact of the current GINA [41], GOLD [42] and allergic rhinitis recommendations on these preferences.

\section{Aim}

Therefore, the aim of the study was the assessment of doctors' preferences in pharmacotherapy of asthma, COPD or allergic rhinitis in relation to concomitant diseases.

\section{Material and methods}

In this observational survey, 11,310 outpatients with asthma, COPD or allergic rhinitis were interviewed nationwide by 319 general practitioners, pulmonologists, allergists, laryngologists and paediatricians from March to November 2016. Doctors participating in the study were recruited by medical representatives. Characteristics of the surveyed population are summarized in Table 1.

The two-part questionnaire consisted of several dichotomous and multiple choice questions. The first part of the questionnaire included the doctor's demographic data (specialization, internship, place of work) and question about therapeutic decisions taken in patients with asthma, COPD and allergic rhinitis with comorbidities, as well as factors determining these decisions.

The second part of the questionnaire included the patient's demographic data (gender, age, place of residence, education level) and clinical data: primary diagnosis (asthma/COPD/allergic rhinitis), disease duration, severity of the disease (for asthma: controlled asthma, partially controlled asthma/uncontrolled asthma according to GINA; for COPD: category from A to D according to GOLD; for allergic rhinitis: mild/moderate/severe), treatment used due to primary disease (divided into groups of drugs, depending on the primary diagnosis), comorbidities (allergic rhinitis, allergic conjunctivitis, chronic sinusitis, gastroesophageal reflux disease, overweight, obesity, type 1 and type 2 diabetes, sleep apnoea syndrome, COPD, depression, hypertension, ischaemic heart disease, other diseases on the basis of an ICD-10 code), and comorbidities medication.

\section{Statistical analysis}

The statistical analysis was performed using the Statistica 10.0 PL (Cracow, Poland) software package. Vari- 
Table 1. Characteristics of doctors participating in the study $(N=319)$

\begin{tabular}{lc}
\hline Variable & Result \\
\hline Specialization, $n$ (\%): & $16(5.0)$ \\
\hline Family medicine & $210(66.0)$ \\
\hline Pulmonology & $64(20.0)$ \\
\hline Allergology & $3(1.0)$ \\
\hline Laryngology & $26(8.0)$ \\
\hline Paediatrics & $0(0)$ \\
\hline Internship, $n$ (\%) [years]: & $13(4.0)$ \\
\hline$\leq 10$ & $46(14.0)$ \\
\hline $11-15$ & $260(82.0)$ \\
\hline $16-20$ & $76(24.0)$ \\
\hline$>20$ & $0(0)$ \\
\hline Basic work place, $n$ (\%): & $160(50.0)$ \\
\hline Public hospital & $57(18.0)$ \\
\hline Private hospital & $26(8.0)$ \\
\hline Public outpatient clinic & $3(1.0)$ \\
\hline Private clinic & $192(60.0)$ \\
\hline Private outpatient practice & $124(39.0)$ \\
\hline Place in which the doctor works, $n$ (\%): & \\
\hline Rural & \\
\hline Town $\leq 200$ 000 residents & \\
\hline City $>$ & 200 000 residents \\
\hline
\end{tabular}

Variable

Result

The most frequent therapeutic decisions taken in patients with COPD, $n(\%)$ :

\begin{tabular}{lc}
\hline Anticholinergic & $156(49.0)$ \\
\hline Short-acting inhaled $\beta_{2}$-mimetic & $83(26.0)$ \\
\hline Inhaled glucocorticosteroids & $32(10.0)$ \\
\hline Long-acting inhaled $\beta_{2}$-mimetic & $188(59.0)$ \\
\hline Theophylline & $6(2.0)$ \\
\hline Oral glucocorticosteroids & $0(0)$ \\
\hline Indacaterol & $3(1.0)$ \\
\hline Inhibitor of phosphodiesterase 4 & $6(2.0)$ \\
\hline
\end{tabular}

The most important factors influencing these therapeutic decisions, $n$ (\%):

\begin{tabular}{lc}
\hline Patient age & $121(38.0)$ \\
\hline $\begin{array}{l}\text { GOLD recommendations taking into account } \\
\text { the severity of the disease }\end{array}$ & $265(83.0)$ \\
\hline Occurrence of concomitant diseases & $128(40.0)$ \\
\hline Interactions with other drugs & $96(30.0)$ \\
\hline Impact on quality of life & $156(49.0)$ \\
\hline
\end{tabular}

Frequent therapeutic decisions taken in patients with allergic rhinitis, $n(\%)$ :

\begin{tabular}{lc}
\hline Antihistamine I generation & $19(6.0)$ \\
\hline Antihistamine II generation & $150(47.0)$ \\
\hline Antihistamine III generation & $260(80.0)$ \\
\hline Drugs reducing nasal congestion & $93(29.0)$ \\
\hline Nasal glucocorticosteroids & $297(93.0)$ \\
\hline
\end{tabular}

asthma, $n(\%)$

\begin{tabular}{lc}
\hline Short-acting inhaled $\beta_{2}$-mimetic & $128(40.0)$ \\
\hline Inhaled glucocorticosteroids & $268(84.0)$ \\
\hline Antileukotriene & $51(16.0)$ \\
\hline Long-acting inhaled $\beta_{2}$-mimetic & $61(19.0)$ \\
\hline Long-acting anticholinergic & $0(0)$ \\
\hline Theophylline & $0(0)$ \\
\hline Oral glucocorticosteroids & $0(0)$ \\
\hline Antibody anti-lgE & $0(0)$ \\
\hline
\end{tabular}

The most important factors influencing these therapeutic decisions, $n$ (\%):

\begin{tabular}{lc}
\hline Patient age & $83(26.0)$ \\
\hline $\begin{array}{l}\text { Recommendations GINA taking into account } \\
\text { the severity of the disease }\end{array}$ & $277(87.0)$ \\
\hline Occurrence of concomitant diseases & $115(36.0)$ \\
\hline Interactions with other drugs & $112(35.0)$ \\
\hline Impact on quality of life & $179(56.0)$ \\
\hline
\end{tabular}

The most important factors influencing these therapeutic decisions, $n$ (\%):

\begin{tabular}{lc}
\hline Patient age & $115(36.0)$ \\
\hline Speed of the drug & $160(50.0)$ \\
\hline Safety of use & $239(75.0)$ \\
\hline Efficacy & $268(84.0)$ \\
\hline Severity of symptoms & $239(75.0)$ \\
\hline Minimal effect on the central nervous system & $160(50.0)$ \\
\hline Interactions with other drugs & $131(41.0)$ \\
\hline Comorbidities & $105(33.0)$ \\
\hline Effect of the treatment on quality of life & $179(56.0)$ \\
\hline $\begin{array}{l}\text { The effect of diagnosis of other chronic } \\
\text { disease on modification of treatment for }\end{array}$ & $258(81.0)$ \\
\hline asthma or COPD or allergic rhinitis, $n(\%)$ & \\
\hline Reducing the dose of the drug used, $n(\%)$ & $29(9.0)$ \\
\hline Increasing the dose of the drug used, $n(\%)$ & $16(5.0)$ \\
\hline Changing the current drug used to & $118(37.0)$ \\
\hline a preparation of another group, $n$ (\%) & $38(12.0)$ \\
\hline Adding another drug, $n$ (\%) & $57(18.0)$ \\
\hline Withdrawal of a previously used drug, $n(\%)$
\end{tabular}


able values were presented as percentages and mean values with standard deviations (SD). Separate groups were compared using the $\chi^{2}$ and $\chi^{2}$ for trend tests. A $p<$ 0.05 was considered as statistically significant.

\section{Results}

\section{Characteristics of doctors participating in this study}

The group of participating doctors was dominated by pulmonologists and allergists (66\% and $20 \%$, respectively), working mainly in public outpatient clinics and hospitals in towns and cities. Eighty-two percent of doctors were working for more than 20 years (Table 1).

\section{The therapeutic decision declared by doctors}

Inhaled glucocorticosteroids and short-acting $\beta_{2}$ agonist were most commonly used by patients with asthma. Antileukotriene drugs and inhaled long-acting $\beta_{2}$-agonist were also frequently used. The most important factors influencing the doctors' therapeutic decisions were the GINA recommendations taking into consideration the disease's severity, the impact of the treatment on the patient's quality of life, and the comorbidities and drug interactions (Table 1).

In the population of patients with COPD, inhaled long-acting $\beta_{2}$-agonists and cholinolytics were most commonly used, followed by short-acting $\beta_{2}$-agonists. The severity of the disease, impact of the treatment on the quality of life, and comorbidities and patient's age were all taken into account in addition to GOLD recommendations in the decision making (Table 1).

In the population of patients with allergic rhinitis, nasal glucocorticosteroids and antihistamine III generation drugs were most commonly used. The most important factors influencing the treatment decisions were the efficacy, safety, and severity of the symptoms. Furthermore, comorbidities were determined as a very important factor influencing the therapeutic decisions for approximately $1 / 3$ of doctors and as an important factor for $55 \%$ of doctors (Table 1).

\section{The therapeutic decision taken in patients with asthma, COPD and allergic rhinitis and reported comorbidities}

Thirty-seven percent of doctors declared that a diagnosis of de novo comorbidities most frequently resulted in a change of the used drug to a different one from another group, however cases of drug discontinuation or introduction were also common (Table 1).

Inhaled glucocorticosteroids were most commonly used in the treatment of asthma despite the co-occurrence of hypertension, type 2 diabetes, cardiovascular diseases and sleep apnoea (Table 2). However, the usage frequency of this drug was slightly decreased in such groups in favour of the increased usage of long-acting $\beta_{2}$-mimetics in comparison to the above described declaration related to the general population diagnosed with asthma. Similarly, in the treatment of COPD with comorbidities, inhaled long-acting $\beta_{2}$-mimetics were most commonly used (Table 2). Nevertheless, in groups with comorbidities the use of inhaled short-acting $\beta_{2}$-mimetics was increased in comparison to the above-described declaration related to the general population with COPD. In the treatment of allergic rhinitis, independently of comorbidities, nasal glucocorticosteroids and antihistaminic III generation drugs were the most common treatment (Table 2).

\section{Study group characteristics}

The study group was dominated by urban residents with vocational and secondary education, suffering from asthma. Characteristics of the surveyed population are summarized in Table 3.

Among the patients with asthma, $61.8 \%$ were diagnosed with controlled asthma. Uncontrolled asthma occurred in $1.3 \%$ of the population. Among the patients suffering from COPD, $48.0 \%$ were in the B category and $25.5 \%$ in the C category according to the GOLD recommendation. Among the patients with allergic rhinitis, $61.6 \%$ suffered from the disease's moderate and $32.6 \%$ from mild intensity (Table 4).

The most common treatment for asthma was inhaled glucocorticosteroids and long-acting $\beta_{2}$-mimetics. For COPD the treatment most commonly involved inhaled long-acting $\beta_{2}$-mimetics, cholinolytic drugs and inhaled glucocorticosteroids, whereas for allergic rhinitis - nasal glucocorticosteroids (Table 4).

Comorbidities were reported in $58.5 \%$ of patients with asthma, $80.8 \%$ of patients with COPD and $46.6 \%$ of patients with allergic rhinitis (Table 4).

The most common comorbidities in patients with asthma included hypertension (26.3\%), allergic rhinitis (12.6\%) and the gastroesophageal reflux disease (11.5\%), among patients with COPD it was hypertension (58.3\%), type 2 diabetes (23.2\%), ischemic heart disease (21.8\%) and overweight (20.3\%) whereas in patients with allergic rhinitis - hypertension (17.8\%) and the gastroesophageal reflux disease (13.8\%).

The most important factors influencing the selection of the used asthma treatment were the GINA recommendations taking into account the severity of the disease (94.0\%), patient age (53.0\%) and the impact on the quality of life (48.1\%). For COPD, the most important factors included the GOLD recommendations taking into account the severity of the disease (94.1\%), patient age (63.8\%) and the impact on the quality of life (57.9\%). For allergic rhinitis, such factors involved the recommendations taking into account the severity of the disease (97.1\%), patient age $(68.5 \%)$ and the impact on the quality of life (66.3\%). The comorbidities and drug interactions were 
Table 2. Therapeutic preferences in the pharmacotherapy for asthma, COPD or allergic rhinitis and concomitant diseases

\begin{tabular}{|c|c|c|c|}
\hline Variable & Rare & Frequent & Most common \\
\hline \multicolumn{4}{|c|}{ Drugs used in patients with asthma and concomitant hypertension, $n(\%)$ : } \\
\hline Short-acting inhaled $\beta_{2}$-mimetic & $93(29.0)$ & $137(43.0)$ & $89(28.0)$ \\
\hline Inhaled glucocorticosteroids & $41(13.0)$ & $46(14.0)$ & $233(73.0)$ \\
\hline Antileukotriene & $76(24.0)$ & $172(54.0)$ & $70(22.0)$ \\
\hline Long-acting inhaled $\beta_{2}$-mimetic & $64(20.0)$ & $153(48.0)$ & $102(32.0)$ \\
\hline Long-acting anticholinergic & $204(64.0)$ & $99(31.0)$ & $16(5.0)$ \\
\hline Theophylline & $201(63.0)$ & $108(34.0)$ & $9(3.0)$ \\
\hline Oral glucocorticosteroids & $230(72.0)$ & $86(27.0)$ & $3(1.0)$ \\
\hline Antibody anti-lgE & $290(91.0)$ & $19(6.0)$ & $9(3.0)$ \\
\hline \multicolumn{4}{|c|}{ Drugs used in patients with asthma and concomitant type 2 diabetes, $n(\%)$ : } \\
\hline Short-acting inhaled $\beta_{2}$-mimetic & $86(27.0)$ & $115(36.0)$ & $118(37.0)$ \\
\hline Inhaled glucocorticosteroids & $61(19.0)$ & $57(18.0)$ & $249(78.0)$ \\
\hline Antileukotriene & $76(24.0)$ & $169(53.0)$ & $73(23.0)$ \\
\hline Long-acting inhaled $\beta_{2}$-mimetic & $61(19.0)$ & $137(43.0)$ & $121(38.0)$ \\
\hline Long-acting anticholinergic & $223(70.0)$ & $80(25.0)$ & $16(5.0)$ \\
\hline Theophylline & $195(61.0)$ & $115(36.0)$ & $9(3.0)$ \\
\hline Oral glucocorticosteroids & $268(84.0)$ & $51(16.0)$ & $0(0)$ \\
\hline Antibody anti-lgE & $287(90.0)$ & $16(5.0)$ & $16(5.0)$ \\
\hline \multicolumn{4}{|c|}{ Drugs used in patients with asthma and concomitant cardiovascular diseases, $n(\%)$ : } \\
\hline Short-acting inhaled $\beta_{2}$-mimetic & $93(29.0)$ & $137(43.0)$ & $89(28.0)$ \\
\hline Inhaled glucocorticosteroids & $35(11.0)$ & $38(12.0)$ & $246(77.0)$ \\
\hline Antileukotriene & $80(25.0)$ & $175(55.0)$ & $64(20.0)$ \\
\hline Long-acting inhaled $\beta_{2}$-mimetic & $51(16.0)$ & $166(52.0)$ & $102(32.0)$ \\
\hline Long-acting anticholinergic & $198(62.0)$ & $105(33.0)$ & $16(5.0)$ \\
\hline Theophylline & $214(67.0)$ & $99(31.0)$ & $6(2.0)$ \\
\hline Oral glucocorticosteroids & $258(81.0)$ & $57(18.0)$ & $3(1.0)$ \\
\hline Antibody anti-lgE & $281(88.0)$ & $26(8.0)$ & $13(4.0)$ \\
\hline \multicolumn{4}{|c|}{ Drugs used in patients with asthma and concomitant sleep apnoea, $n(\%):$} \\
\hline Short-acting inhaled $\beta_{2}$-mimetic & $83(26.0)$ & $108(34.0)$ & $128(40.0)$ \\
\hline Inhaled glucocorticosteroids & $54(17.0)$ & $41(13.0)$ & $223(70.0)$ \\
\hline Antileukotriene & $93(29.0)$ & $160(50.0)$ & $67(21.0)$ \\
\hline Long-acting inhaled $\beta_{2}$-mimetic & $54(17.0)$ & $134(42.0)$ & $131(41.0)$ \\
\hline Long-acting anticholinergic & $204(64.0)$ & $89(28.0)$ & $26(8.0)$ \\
\hline Theophylline & $169(53.0)$ & $137(43.0)$ & $13(4.0)$ \\
\hline Oral glucocorticosteroids & $242(76.0)$ & $73(23.0)$ & $3(1.0)$ \\
\hline Antibody anti-lgE & $284(89.0)$ & $19(6.0)$ & $16(5.0)$ \\
\hline \multicolumn{4}{|c|}{ Drugs used in patients with COPD and concomitant hypertension, $n$ (\%): } \\
\hline Short-acting inhaled $\beta_{2}$-mimetic & $102(32.0)$ & $102(32.0)$ & $115(36.0)$ \\
\hline Inhaled glucocorticosteroids & $70(22.0)$ & $172(54.0)$ & $76(24.0)$ \\
\hline Antileukotriene & $192(60.0)$ & $108(34.0)$ & $19(6.0)$ \\
\hline Long-acting inhaled $\beta_{2}$-mimetic & $64(20.0)$ & $115(36.0)$ & $140(44.0)$ \\
\hline Long-acting anticholinergic & $102(32.0)$ & $86(27.0)$ & $131(41.0)$ \\
\hline
\end{tabular}


The pharmacotherapy preferred by doctors in treatment of patients diagnosed with asthma or chronic obstructive pulmonary disease or allergic rhinitis and concomitant diseases: an epidemiological analysis

Table 2. Cont.

\begin{tabular}{|c|c|c|c|}
\hline Variable & Rare & Frequent & Most common \\
\hline Theophylline & $179(56.0)$ & $128(40.0)$ & $13(4.0)$ \\
\hline Oral glucocorticosteroids, n (\%) & $258(81.0)$ & $57(18.0)$ & $3(1.0)$ \\
\hline \multicolumn{4}{|c|}{ Drugs used in patients with COPD and concomitant type 2 diabetes, $n(\%)$ : } \\
\hline Short-acting inhaled $\beta_{2}$-mimetic & $99(31.0)$ & $115(36.0)$ & $105(33.0)$ \\
\hline Inhaled glucocorticosteroids & $89(28.0)$ & $160(50.0)$ & $70(22.0)$ \\
\hline Antileukotriene & $210(66.0)$ & $80(25.0)$ & $29(9.0)$ \\
\hline Long-acting inhaled $\beta_{2}$-mimetic & $54(17.0)$ & $93(29.0)$ & $172(54.0)$ \\
\hline Long-acting anticholinergic & $102(32.0)$ & $89(28.0)$ & $128(40.0)$ \\
\hline Theophylline & $265(83.0)$ & $51(16.0)$ & $3(1.0)$ \\
\hline Oral glucocorticosteroids & $300(94.0)$ & $19(6.0)$ & $0(0)$ \\
\hline \multicolumn{4}{|c|}{ Drugs used in patients with COPD and concomitant cardiovascular diseases, $n(\%)$ : } \\
\hline Short-acting inhaled $\beta_{2}$-mimetic & $99(31.0)$ & $112(35.0)$ & $108(34.0)$ \\
\hline Inhaled glucocorticosteroids & $83(26.0)$ & $166(52.0)$ & $70(22.0)$ \\
\hline Antileukotriene & $201(63.0)$ & $83(26.0)$ & $35(11.0)$ \\
\hline Long-acting inhaled $\beta_{2}$-mimetic & $61(19.0)$ & $118(37.0)$ & $140(44.0)$ \\
\hline Long-acting anticholinergic & $108(34.0)$ & $73(23.0)$ & $137(43.0)$ \\
\hline Theophylline & $195(61.0)$ & $118(37.0)$ & $6(2.0)$ \\
\hline Oral glucocorticosteroids & $271(85.0)$ & $46(14.0)$ & $3(1.0)$ \\
\hline \multicolumn{4}{|c|}{ Drugs used in patients with COPD and concomitant sleep apnoea, $n$ (\%): } \\
\hline Short-acting inhaled $\beta_{2}$-mimetic & $93(29.0)$ & $115(36.0)$ & $112(35.0)$ \\
\hline Inhaled glucocorticosteroids & $86(27.0)$ & $147(46.0)$ & $86(27.0)$ \\
\hline Antileukotriene & $217(68.0)$ & $83(26.0)$ & $19(6.0)$ \\
\hline Long-acting inhaled $\beta_{2}$-mimetic & $51(16.0)$ & $115(36.0)$ & $153(48.0)$ \\
\hline Long-acting anticholinergic & $83(26.0)$ & $80(25.0)$ & $156(49.0)$ \\
\hline Theophylline & $175(55.0)$ & $124(39.0)$ & $19(6.0)$ \\
\hline Oral glucocorticosteroids & $274(86.0)$ & $38(12.0)$ & $6(2.0)$ \\
\hline \multicolumn{4}{|c|}{ Drugs used in patients with allergic rhinitis and concomitant hypertension, $n(\%)$ : } \\
\hline Antihistamine I generation & $249(78.0)$ & $61(19.0)$ & $9(3.0)$ \\
\hline Antihistamine II generation & $90(30.0)$ & $131(41.0)$ & $93(29.0)$ \\
\hline Antihistamine III generation & $76(24.0)$ & $115(36.0)$ & $128(40.0)$ \\
\hline Drugs reducing nasal congestion & $195(61.0)$ & $112(35.0)$ & $13(4.0)$ \\
\hline Nasal glucocorticosteroids & $61(19.0)$ & $76(24.0)$ & $182(57.0)$ \\
\hline \multicolumn{4}{|c|}{ Drugs used in patients with allergic rhinitis and concomitant type 2 diabetes, $n(\%)$ : } \\
\hline Antihistamine I generation & $252(79.0)$ & $57(18.0)$ & $9(3.0)$ \\
\hline Antihistamine II generation & $112(35.0)$ & $140(44.0)$ & $67(21.0)$ \\
\hline Antihistamine III generation & $73(23.0)$ & $115(36.0)$ & $131(41.0)$ \\
\hline Drugs reducing nasal congestion & $172(54.0)$ & $128(40.0)$ & $19(6.0)$ \\
\hline Nasal glucocorticosteroids & $207(65.0)$ & $48(15.0)$ & $64(20.0)$ \\
\hline \multicolumn{4}{|c|}{ Drugs used in patients with allergic rhinitis and concomitant cardiovascular diseases, $n(\%)$ : } \\
\hline Antihistamine I generation & $281(88.0)$ & $32(10.0)$ & $6(2.0)$ \\
\hline Antihistamine II generation & $118(37.0)$ & $128(40.0)$ & $73(23.0)$ \\
\hline Antihistamine III generation & $73(23.0)$ & $128(40.0)$ & $118(37.0)$ \\
\hline Drugs reducing nasal congestion & $179(56.0)$ & $124(39.0)$ & $16(5.0)$ \\
\hline Nasal glucocorticosteroids & $61(19.0)$ & $86(27.0)$ & $172(54.0)$ \\
\hline
\end{tabular}

Drugs used in patients with allergic rhinitis and concomitant sleep apnoea, $n(\%)$ : 
Table 2. Cont.

\begin{tabular}{lccc}
\hline Variable & Rare & Frequent & Most common \\
\hline Antihistamine I generation & $252(79.0)$ & $54(17.0)$ & $13(4.0)$ \\
\hline Antihistamine II generation & $134(42.0)$ & $128(40.0)$ & $57(18.0)$ \\
\hline Antihistamine III generation & $83(26.0)$ & $115(36.0)$ & $121(38.0)$ \\
\hline Drugs reducing nasal congestion & $160(50.0)$ & $134(42.0)$ & $26(8.0)$ \\
\hline Nasal glucocorticosteroids & $61(19.0)$ & $70(22.0)$ & $188(59.0)$ \\
\hline
\end{tabular}

Table 3. Study group characteristics $(N=11,310)$

\begin{tabular}{ll}
\hline Parameter & Result \\
\hline Age, mean \pm SD [years] & $49.7 \pm 19.6$ \\
\hline Gender, $n$ (\%): & $5,497(48.6)$ \\
\hline Male & $5,813(51.4)$ \\
\hline Female & $1,482(13.1)$ \\
\hline Education, $n$ (\%): & $3,608(31.9)$ \\
\hline Primary & $3,992(35.3)$ \\
\hline Vocational & $2,228(19.7)$ \\
\hline Secondary & \\
\hline Higher & $2,895(25.6)$ \\
\hline Place of residence, $n$ (\%): & $6,662(58.9)$ \\
\hline Rural & $1,753(15.5)$ \\
\hline Town $\leq 200$ 000 residents & \\
\hline City $>200$ 000 residents & $5,492(48.6)$ \\
\hline Primary diagnosis, $n$ (\%): & $2,868(25.3)$ \\
\hline Asthma & $2,950(26.1)$ \\
\hline COPD &
\end{tabular}

the least common factor taken into consideration in patients diagnosed with asthma $(37.5 \%$ and $39.3 \%$, respectively) - Table 4.

\section{Discussion}

Doctors participating in this study most commonly declared the use of inhaled glucocorticosteroids and then short-acting $\beta_{2}$-agonists for asthma treatment. This strategy is in accordance with grade 2 therapy and secondly with grade 1 therapy recommended by GINA [41]. It suggests that subjects with mild asthma dominated among their patients when initiating the treatment. This hypothesis is supported by the results assessing the factors determining the therapeutic decisions among which the most important were GINA recommendations taking into consideration the severity of the disease. It should be noted that inhaled glucocorticosteroids were most commonly used for asthma treatment regardless of the co-occurrence of hypertension, type 2 diabetes, cardiovascular diseases and sleep apnoea. However, their use in patients with comorbidities slightly decreased in favour of long-acting $\beta_{2}$-mimetics. It is interesting as this strategy is not in accordance with grade 3 therapy recommended by GINA [41]. Thus, these decisions cannot be explained by asthma exacerbations. On the other hand, inhaled glucocorticosteroids are used in low doses and their absorption from the respiratory tract into the systemic circulation is low. Therefore, their impact on the course of comorbidities is negligible. Further studies are necessary to explain the factors that influenced these therapeutic preferences.

When comparing the physicians' declarations with the results in the study group of patients with asthma, some differences appear concerning the use of long-acting $\beta_{2}$-mimetics that were more commonly prescribed than short-acting inhaled $\beta_{2}$-mimetics. The comorbidities occurred in $58.5 \%$ of patients with asthma, with the most common one being hypertension. The most important factors indicated by the physician as justification of the treatment for asthma were the GINA recommendation taking into account the severity of the disease, whereas comorbidities were the least important factor taken into account.

In the population of patients with COPD, doctors most commonly declared the use of inhaled long-acting $\beta_{2}$-agonist and cholinolytics, followed by inhaled shortacting $\beta_{2}$-agonists. This selection of drugs is recommended by the GOLD strategy as the treatment of first choice in B-D class COPD [42]. The questionnaire did not include questions concerning the choice of drugs in relation to the severity of the disease. However, our results suggest that among the study population, patients with this stage of the disease were dominant. This hypothesis is supported by the results assessing factors determining the therapeutic decisions among which the most important factor was the GOLD recommendations tailored to the severity of the disease. It should be noted that inhaled long-acting $\beta_{2}$-mimetics were most commonly prescribed in COPD treatment regardless of the CO-Occurrence of hypertension, type 2 diabetes, cardiovascular diseases and sleep apnoea. However, in groups with comorbidities, an increased use of inhaled short-acting $\beta_{2}$-mimetics in comparison to the declaration was noted 
The pharmacotherapy preferred by doctors in treatment of patients diagnosed with asthma or chronic obstructive pulmonary disease or allergic rhinitis and concomitant diseases: an epidemiological analysis

Table 4. Clinical characteristics of study subgroups

\begin{tabular}{|c|c|c|c|}
\hline Parameter & $\begin{array}{l}\text { Asthma } \\
(N=5492)\end{array}$ & $\begin{array}{c}\text { COPD } \\
(N=2868)\end{array}$ & $\begin{array}{l}\text { Allergic rhinitis } \\
\qquad(N=2950)\end{array}$ \\
\hline \multicolumn{4}{|l|}{ Duration of the disease, $n(\%)$ : } \\
\hline$<3$ months & $71(1.3)$ & $20(0.7)$ & $12(0.4)$ \\
\hline $3-6$ months & $71(1.3)$ & $86(3.0)$ & $32(1.1)$ \\
\hline $6-12$ months & $132(2.4)$ & $43(1.5)$ & $106(3.6)$ \\
\hline $1-2$ years & $434(7.9)$ & $138(4.8)$ & $212(7.2)$ \\
\hline $2-3$ years & $533(9.7)$ & $370(12.9)$ & $448(15.2)$ \\
\hline $3-4$ years & $0(0)$ & $0(0)$ & $32(1.1)$ \\
\hline $4-5$ years & $895(16.3)$ & $677(23.6)$ & $555(18.8)$ \\
\hline$>5$ years & $3,335(60.9)$ & $1,534(53.5)$ & $1,549(52.5)$ \\
\hline \multicolumn{4}{|l|}{ Severity of asthma according to GINA, $n(\%)$ : } \\
\hline Controlled asthma & $3394(61.8)$ & - & - \\
\hline Partially controlled asthma & $2,027(36.9)$ & - & - \\
\hline Uncontrolled asthma & $71(1.3)$ & - & - \\
\hline \multicolumn{4}{|l|}{ Severity of COPD according to GOLD, $n$ (\%): } \\
\hline Category A & - & $338(11.8)$ & - \\
\hline Category B & - & $1,377(48.0)$ & - \\
\hline Category C & - & $731(25.5)$ & - \\
\hline Category D & - & $424(14.8)$ & - \\
\hline \multicolumn{4}{|l|}{ Severity of allergic rhinitis, $n$ (\%): } \\
\hline Mild & - & - & $962(32.6)$ \\
\hline Moderate & - & - & $1,817(61.6)$ \\
\hline Severe & - & - & $171(5.8)$ \\
\hline \multicolumn{4}{|l|}{ Treatment used for asthma, $n(\%)$ : } \\
\hline Short-acting inhaled $\beta_{2}$-mimetic & $1,307(23.8)$ & - & - \\
\hline Inhaled glucocorticosteroids & $1,560(28.4)$ & - & - \\
\hline Antileukotriene & $972(17.7)$ & - & - \\
\hline Long-acting inhaled $\beta_{2}$-mimetic & $1,400(25.5)$ & - & - \\
\hline Long-acting anticholinergic & $93(1.7)$ & - & - \\
\hline Theophylline & $121(2.2)$ & - & - \\
\hline Oral glucocorticosteroids & $33(0.6)$ & - & - \\
\hline Antibody anti-lgE & $11(0.2)$ & - & - \\
\hline \multicolumn{4}{|l|}{ Treatment used for COPD, $n$ (\%): } \\
\hline Anticholinergic & - & $576(20.1)$ & - \\
\hline Short-acting inhaled $\beta_{2}$-mimetic & - & $424(14.8)$ & - \\
\hline Inhaled glucocorticosteroids & - & $562(19.6)$ & - \\
\hline Long-acting inhaled $\beta_{2}$-mimetic & - & $843(29.4)$ & - \\
\hline Theophylline & - & $330(11.5)$ & - \\
\hline Oral glucocorticosteroids & - & $43(1.5)$ & - \\
\hline Indacaterol & - & $69(2.4)$ & - \\
\hline An inhibitor of phosphodiesterase 4 & - & $20(0.7)$ & - \\
\hline
\end{tabular}


Table 4. Cont.

\begin{tabular}{|c|c|c|c|}
\hline Parameter & $\begin{array}{l}\text { Asthma } \\
(N=5492)\end{array}$ & $\begin{array}{c}\text { COPD } \\
(N=2868)\end{array}$ & $\begin{array}{l}\text { Allergic rhinitis } \\
\qquad(N=2950)\end{array}$ \\
\hline \multicolumn{4}{|l|}{ Treatment used for allergic rhinitis, $n$ (\%): } \\
\hline Antihistamine I generation & - & - & $68(2.3)$ \\
\hline Antihistamine II generation & - & - & $560(19.0)$ \\
\hline Antihistamine III generation & - & - & $723(24.5)$ \\
\hline Drugs reducing nasal congestion & - & - & $115(3.9)$ \\
\hline Nasal glucocorticosteroids & - & - & $1,484(50.3)$ \\
\hline Concomitant diseases, $n(\%)$ & $3,213(58.5)$ & $2,317(80.8)$ & $1,369(46.4)$ \\
\hline Allergic rhinitis, $n(\%)$ & $692(12.6)$ & $20(0.7)$ & - \\
\hline Allergic conjunctivitis, $n(\%)$ & $373(6.8)$ & $43(1.5)$ & $183(6.2)$ \\
\hline Chronic sinusitis, $n(\%)$ & $143(2.6)$ & $52(1.8)$ & $204(6.9)$ \\
\hline Gastroesophageal reflux disease, $n(\%)$ & $632(11.5)$ & $508(17.7)$ & $408(13.8)$ \\
\hline Obesity, $n(\%)$ & $313(5.7)$ & $244(8.5)$ & $139(4.7)$ \\
\hline Overweight, $n(\%)$ & $533(9.7)$ & $582(20.3)$ & $236(8.0)$ \\
\hline Type 1 diabetes, $n(\%)$ & $49(0.9)$ & $149(5.2)$ & $41(1.4)$ \\
\hline Type 2 diabetes, $n(\%)$ & $500(9.1)$ & $665(23.2)$ & $118(4.0)$ \\
\hline Sleep apnoea syndrome, $n(\%)$ & $49(0.9)$ & $138(4.8)$ & $32(1.1)$ \\
\hline Depression, $n(\%)$ & $170(3.1)$ & $138(4.8)$ & $41(1.4)$ \\
\hline Hypertension, $n(\%)$ & $1444(26.3)$ & $1,672(58.3)$ & $525(17.8)$ \\
\hline Ischemic heart disease, $n(\%)$ & $341(6.2)$ & $652(21.8)$ & $41(1.4)$ \\
\hline \multicolumn{4}{|c|}{ Factors that influence the choice of the treatment used for asthma or COPD or allergic rhinitis, $n$ (\%): } \\
\hline Patient age & 2,911 (53.0) & $1,830(63.8)$ & $2,021(68.5)$ \\
\hline $\begin{array}{l}\text { GINA or GOLD recommendations or allergic rhinitis } \\
\text { taking into account the severity of the disease }\end{array}$ & $5,162(94.0)$ & $2,699(94.1)$ & $2,864(97.1)$ \\
\hline Occurrence of concomitant diseases & $2,060(37.5)$ & $1,554(54.2)$ & $1,572(53.3)$ \\
\hline Interactions with other drugs & $2,158(39.3)$ & $1,417(49.4)$ & $1,528(51.8)$ \\
\hline Impact on quality of life & $2,642(48.1)$ & $1,661(57.9)$ & $1,956(66.3)$ \\
\hline Price of the drug & $1,032(18.8)$ & $221(7.7)$ & $941(31.9)$ \\
\hline
\end{tabular}

for general COPD populations. This may indicate frequent occurrence of dyspnoea among patients with comorbidities. The hypothesis is supported by the observation that COPD exacerbations are most common among patients with comorbidities such as diabetes and cardiovascular diseases [29].

In the observed group of patients, the most common COPD medications were inhaled long-acting $\beta_{2}$-mimetics, cholinolytic drugs and inhaled glucocorticosteroids. The comorbidities occurred in $80.8 \%$ of patients with COPD, with the most common one being hypertension. The most important factors influencing the choice of asthma treatment were GINA recommendations tailored to the severity of the disease. It is worth mentioning that comorbidities were not among the three most important factors influencing the therapeutic decisions. However, a relatively common use of inhaled glucocorticosteroids suggests their use for the prevention of exacerbations in COPD patients at high risk of exacerbation, which is in accordance with GOLD recommendations [42].

In the population of patients with allergic rhinitis, doctors most commonly declared the use of nasal glucocorticosteroids and antihistamine III generation drugs. Antihistamine drugs, according to recommendations, are the first-line treatment of allergic rhinitis together with preparations that reduce nasal congestion. However, an additional use of glucocorticosteroids is recommended when the therapy is not effective [43]. Thus, the declared decisions are partially inconsistent with the recommendations. On the other hand, glucocorticosteroids are most effective in removing all symptoms of allergic rhinitis [43]. Indeed, the doctors determined effectiveness as the most important factor in the decision-making process. It should be noted that the choice of nasal glucocor- 
ticosteroids and antihistamine III generation drugs was not affected by the occurrence of comorbidities.

The frequency of nasal glucocorticosteroids prescribed in study patients with allergic rhinitis is in line with doctors' preferences. The most important factors influencing the selection of the treatment for allergic rhinitis were the recommendations tailored to the severity of the disease. Whereas comorbidities (reported in $46.6 \%$ of patients) were not among the three most important factors influencing therapeutic choices.

\section{Conclusions}

The co-occurrence of chronic diseases was most frequent among patients diagnosed with COPD. The treatment of asthma, COPD and allergic rhinitis is consistent with international recommendations and the occurrence of concomitant diseases did not significantly influence the therapeutic preferences and decisions.

\section{Acknowledgments}

The study was carried out as a research project supported by a scientific grant of Adamed Ltd. organized by Europharma M. Rachtan Ltd.

Participating general practitioners received payment for completing surveys.

\section{Conflict of interest}

The authors declare no conflict of interest.

\section{References}

1. Global strategy for asthma management and prevention. Available at: www.ginaasthma.com

2. Smoliński B, Sybilski AJ, Raciborski F, et al. Występowanie astmy oskrzelowej u dzieci, młodzieży i młodych dorosłych w Polsce w świetle badania ECAP. Alerg Astma Immunol 2009; 14: 27-34.

3. Adams RJ, Wilson DH, Taylor AW, et al. Coexistent chronic conditions and asthma quality of life: a population-based study. Chest 2006; 129: 285-91.

4. Aubas C, Bourdin A, Aubas P, et al. Role of comorbid condition in asthma hospitalizations in the south of France. Allergy 2013; 68: 637-43.

5. Roberts NJ, Lewsey JD, Gillies M, et al. Time trends in 30 day case-fatality following hospitalisation for asthma in adults in Scotland: a retrospective cohort study from 1981 to 2009. Respir Med 2013; 107: 1172-7.

6. Zhang T, Carleton BC, Prosser R, et al. The added burden of comorbidity in patients with asthma. J Asthma 2009; 46: 1021-6.

7. Boulet LP. Influence of comorbid conditions on asthma. Eur Respir J 2009; 33: 897-906.

8. van Manen JG, Bindels PJ, Jzermans CJ, et al. Prevalence of comorbidity in patients with a chronic airway obstruction and controls over the age of 40. J Clin Epidemiol 2001; 54: 287-93.
9. Prosser R, Carleton B, Smith A. The comorbidity burden of the treated asthma patient population in British Columbia. Chronic Dis Can 2010; 30: 46-55.

10. Sibbald B, Rink E. Epidemiology of seasonal and perennial rhinitis. Clinical presentation and medical history. Thorax 1991; 46: 895-901.

11. Leynaert B, Bosquet J, Neukrich C, et al. Perennial rhinitis: an independent risk factor for asthma in nonatopic subjects: results from the European Community Respiratory Health Survey. J Allergy Clin Immunol 1999; 104: 301-4.

12. Bresciani M, Paradis L, Des Roches A, et al. Rhinosinusitis in severe asthma. J Allergy Clin Immunol 2001; 107: 73-80.

13. Soriano JB, Davis KJ, Coleman B, et al. The proportional Venn diagram of obstructive lung disease: two approximations from the United States and the United Kingdom. Chest 2003; 124: 474-81.

14. Persson C, Bengtsson C, Lapidus L, et al. Peak expiratory flow and risk of cardiovascular disease and death. Am J Epidemiol 1986; 124: 942-8.

15. Dogra S, Ardern Cl, Baker J. The relationship between age of onset and cardiovascular disease in Canadians. J Asthma 2007; 44: 849-54.

16. Schanen JG, Iribarren C, Shahar E, et al. Asthma and incident cardiovascular disease: the Atherosclerosis Risk in Communities Study. Thorax 2005; 60: 633-8.

17. Litonjua AA, Lazarus R, Sparrow D, et al. Lung function in type 2 diabetes: the Normative Aging Study. Respir Med 2005; 99: 1583-90.

18. Hashemzadeh M, Movahed MR. The occurrence of asthma in hospitalized patients with type 2 diabetes mellitus. Intern Med J 2009; 39: 699-701.

19. Guh DP, Zhang W, Bansback N, et al. The incidence of comorbidities related to obesity and overweight: a systematic review and meta-analysis. BMC Public Health 2009; 9: 88.

20. Lavoie KL, Bacon SL, Labrecque M, et al. Higher BMI is associated with worse asthma control and quality of life but not asthma severity. Respir Med 2006; 100: 648-57.

21. Shah R, Yang Y. Health and economic burden of obesity in elderly individuals with asthma in the United States. Popul Health Manag 2015; 18: 186-91.

22. Nejtek VA, Brown ES, Khan D, et al. Prevalence of mood disorders and relationship to asthma severity in patients at an inner-city asthma clinic. Ann Allergy Asthma Immunol 2001; 87: 129-33.

23. Ng TP, Chiam PC, Kua EH. Mental disorders and asthma in the elderly: a population-based study. Int J Geriatr Psychiatry 2007; 22: 668-74.

24. Krauskopf KA, Sofianou A, Goel MS, et al. Depressive symptoms, low adherence, and poor asthma outcomes in the elderly. J Asthma 2013; 50: 260-6.

25. Celli BR, MacNee W. Standards for the diagnosis and treatment of patients with COPD: a summary of the ATS/ERS position paper. Eur Respir J 2004; 23: 932-46.

26. Halbert RJ, Natoli JL, Gano A, et al. Global burden of COPD: systematic review and meta-analysis. Eur Respir J 2006; 28 : 523-32.

27. Jemal A, Ward E, Hao Y, Thun M. Trends in the leading causes of death in the United States, 1970-2002. JAMA 2005; 294: 1255-9.

28. Murray CJL, Lopez AD. Alternative projections of mortality and disability by cause 1990-2020: Global Burden of Disease Study. Lancet 1997; 349: 1498-504. 
29. Holguin F, Folch E, Redd SC, Mannino DM. Comorbidity and mortality in COPD-related hospitalizations in the United States, 1979 to 2001. Chest 2005; 128: 2005-11.

30. Kunik M, Rondy K, Veazey C. Surprisingly high prevalence of anxiety and depression in chronic breathing disorders. Chest 2005; 127: 1205-11.

31. Gudmundsson G, Gislason T, Janson C. Risk factors for rehospitalisation in COPD: role of health status, anxiety and depression. Eur Respir J 2005; 26: 414-9.

32. Voogd J, Wempe J, Koeter G, et al. Depressive symptoms as predictors of mortality in patients with COPD. Chest 2009; 135: 619-25.

33. Naclerio R, Solomon W. Rhinitis and inhalant allergens. JAMA 1997; 278: 1842-8.

34. Nathan RA, Meltzer EO, Selner JC, Sterns W. Prevalence of allergic rhinitis in the United States. J Allergy Clin Immunol 1997; 99: 5808-14.

35. Wright AL, Holberg CJ, Martinez FD, et al. Epidemiology of physician-diagnosed allergic rhinitis in childhood. Pediatrics 1994; 94: 895-901.

36. Breborowicz A, Burchardt B, Pieklik H. Asthma, allergic rhinitis and atopic dermatitis in schoolchildren [Polish]. Pneumonol Alergol Pol 1995; 63: 157-61.

37. Małolepszy J, Liebhart J, Wojtyniak B, et al. Występowanie chorób alergicznych w Polsce. Alerg Astma Immunol 2000; 5 Suppl. 2: 163-9.

38. Storms W, Meltzer EO, Nathan RA, Selner JC. The economic impact of allergic rhinitis. J Allergy Clin Immunol 1997; 88: 820-8.

39. Furukawa CT. The role of allergy in sinusitis in children. J Allergy Clin Immunol 1992; 90: 515-7.

40. Reid PH, Lockey RF, Turtceltaub PC, Plott-Mills TAE. Survey of fatalities from skin testing and immunotherapy, 1985. J Allergy Clin Immunol 1993; 92: 6-15.

41. Global Strategy for Asthma Management and Prevention. Global Initiative for Asthma (GINA), 2006. Available at: www. ginasthma.org

42. Global Strategy for the Diagnosis, Management and Prevention of COPD, Global Initiative for Chronic Obstructive Lung Disease (GOLD) 2011. Available at: http://www.goldcopd. org/.

43. Bousquet J, Reid J, van Weel C, et al. Allergic rhinitis management pocket reference 2008. Allergy 2008; 63: 990-6. 